\title{
Complexity Simulation on Application of Asymmetric Bionic Cross-Section Rod in Pantographs of High-Speed Trains
}

\author{
Yan Cao $\mathbb{D}$, Yu Bai $\mathbb{D}^{\text {, }}$, and Qiangfeng Wang $(\mathbb{D}$ \\ School of Mechatronic Engineering, Xi'an Technological University, Xi'an 710021, China \\ Correspondence should be addressed to Yan Cao; jantonyz@163.com
}

Received 25 May 2018; Accepted 11 July 2018; Published 1 August 2018

Academic Editor: Changzhi Wu

Copyright @ 2018 Yan Cao et al. This is an open access article distributed under the Creative Commons Attribution License, which permits unrestricted use, distribution, and reproduction in any medium, provided the original work is properly cited.

\begin{abstract}
Ground transportation means and aircrafts with high-speed running are composed of many rod components. Aerodynamic noise generated therefrom is very outstanding. Reduction of the aerodynamic noise of rods becomes a hot topic in recent years. Most reported studies are tentative researches on aerodynamic noise of a pantograph or involve noise reduction of the pantograph with using porous materials or reshaping rod surfaces. Through using porous materials and reshaping rod surface, the aerodynamic noise of pantograph can be reduced to a certain extent, but the aerodynamic resistance will be increased and it is not convenient for practical application in engineering. Regarding this situation, the paper explores noise reduction performance of a feather on the back of a carrier pigeon and conducts the bionic design on rod surface. Through numerical simulation, the paper researches noise reduction performance of the bionic structure on the rod surface, reveals the mechanism of bionic noise reduction, and explores noise reduction effects of bionic structural rods on pantographs of the high-speed trains.
\end{abstract}

\section{Introduction}

With the continuous increase of running speed, noise problems of high-speed trains become more and more obvious. When the running speed reaches over $250 \mathrm{~km} / \mathrm{h}$, the aerodynamic noise generated from high-speed train running will exceed wheel track noise and become the major noise source [1-4]. A pantograph is an equipment used by a high-speed train to obtain electric energy from a contact electric grid. It is composed of parts such as a slide plate and an arm rod. The complicated structure form of it brings huge influences on the aerodynamic performance of the high-speed train. When the train runs at a high speed, the concave and convex parts on the train will bring serious disturbance to airflows. As a result, complicated flow separation and a series of eddy shedding and crushing will take place, so that strong far-field aerodynamic pulsation pressure fields will be generated and transformed to aerodynamic noise. When the train running speed reaches $300 \mathrm{~km} / \mathrm{h}$, the aerodynamic noise of the pantograph will become the overriding noise source of high-speed railways. If the train speed is further increased, the aerodynamic noise of the pantograph will become more serious [5-8]. Reduction of pantograph aerodynamic noise has become one of the key technologies used to control the aerodynamic noise of high-speed trains [9-11].

At present, a lot of achievements have been achieved on simulation and reduction of aerodynamic noise of the highspeed train pantograph. King [12] used the dipole point acoustic source to describe aerodynamic noise caused by eddy shedding of the pantograph, finding the linear relationship between far-field aerodynamic noise of the pantograph and the logarithm of train speed. Noger et al. [13] tested the aerodynamic noise source of the pantograph in a lownoise wind tunnel, finding that the leeward side on the pantograph head is a major aerodynamic noise source. Sueki [14] used a porous material on the PS207 pantograph of a Shinkansen high-speed train and conducted a wind tunnel experiment, finding that noise was reduced by $1.9 \mathrm{dBA}$ when the pantograph ran at $360 \mathrm{~km} / \mathrm{h}$. This result indicates that material attributes have great influences on the aerodynamic noise of the pantograph. Hence, material attributes shall be taken into account in a low-noise design of the pantograph. Kurita [15] optimized the structural shape of the pantograph 
head and adopted the novel low-noise pantograph. Noise reduction effects of the low-noise pantograph head shape and novel pantograph were verified in the wind tunnel experiment. Yu et al. [16] designed 3 fairing structures and carried out numerical simulation analysis of the pantograph, finding that noise reduction effects were obvious and the sound pressure level decreased by about $3 \mathrm{~dB}$ after the application of the fairing similar to a windshield structure. Liu et al. [17] adopted a hybrid computation method in which LIU used large eddy simulation to obtain the equivalent aerodynamic noise source of flow fields and then applied it on boundary elements of sound fields, so as to make detailed research of dipole noise source characteristics on the pantograph surface. It was found that the main energy of the pantograph ranged under $1000 \mathrm{~Hz}$ and was mainly centralized within 100 700 Hz. Under the certain train speed, with the increase of frequency, the amplitude of dipole noise source on the pantograph surface decreased. When the frequency increased from $20 \mathrm{~Hz}$ to $5000 \mathrm{~Hz}$, the amplitude of dipole noise source under different train speeds decreased by over $30 \mathrm{~dB}$. Xiao and Shi [11] carried out the simulation computation of different cross-section shapes of the pantograph insulator, finding the noise reduction rule that the optimal insulator cross-section shape is oval, and the long axis of oval shall accord with airflow direction. Zhang et al. [18] conducted numerical simulation researches on different structures and different installation positions of pantograph fairings as well as different arc-rise modes of the twin-type pantograph and other aspects, finding the optimal pantograph layout scheme that the far-field sound pressure level of a whole train can be reduced by $3.2 \mathrm{dBA}$ to the most. Du et al. [19] used the separated eddy turbulence model and acoustic analogy theory to conduct far-field aerodynamic noise prediction of the simplified pantograph. Results show that the cross beam on the pantograph top is the main aerodynamic noise source. Lee and Cho [20] optimized the cross-section shape of the pantograph head and opened holes for drainage on the point pressure positions to reduce the airflow disturbance of the pantograph head. Wind tunnel testing results show that the improved pantograph shape can reduce disturbance at the tail part of the pantograph head and reduce aerodynamic noise.

Most studies above are tentative researches on the aerodynamic noise of the pantograph or involve the noise reduction of the pantograph with coating of porous materials or reshaping of rod surfaces. Through coating of porous materials and rod surface reshaping, the aerodynamic noise of the pantograph can be reduced to a certain extent, but the aerodynamic resistance will be increased and it is not convenient for practical application in engineering. The paper explores the noise reduction performance of the feather on the back of a carrier pigeon and conducts bionic reshaping design on the rod surface. Through numerical simulation, the paper researches the noise reduction performance of the bionic structure on the rod surface, reveals the mechanism of bionic noise reduction, and explores noise reduction effects of bionic structural rods on the pantograph of the high-speed train.

\section{Theory of Numerical Computation}

The basic idea of LES is that spatial low-pass filtering is conducted to turbulence; N-S equation is solved directly for large-scale values; momentum and energy transport effects of small-scale eddies on large-scale eddies are simulated by a subgrid scale model. During transmission of turbulence energy, large-scale eddies nearly contain all the turbulence energy, while small-scale eddies mainly dissipate turbulence energy. Through direct computation of largescale eddies, most flow information in turbulence motion can be kept. In addition, large-scale eddies are closely correlated with geometric boundary conditions of flow. Small-scale eddies are approximately isotropous and are deemed to suffer little influences from geometric boundaries and large-eddy motion. Hence, application of the subgrid mode in the simulation of small-scale eddies is applicable to various types of turbulence motion. It is fair to say that the LES method is a neural method between DNS and RANS. In comparison with the RANS method, the LES method can further reflect true details of turbulence, so high computation accuracy can be ensured. The control equation of LES is still the N-S equation of incompressible fluids. The large-scale speed in LES is the smoothing speed, which is defined as

$$
\bar{u}_{i}(x, t)=\int G\left(x, x^{\prime}, \Delta\right) u_{i}\left(x^{\prime}, t\right) d x^{\prime},
$$

where $G\left(x, x^{\prime}, \Delta\right)$ is a smoothing function, which is used to calibrate large eddies and filter out small eddies and $\Delta$ denotes the size of the filtering mesh. It is assumed that the filtering course and the derivation course can be changed. It is applied to the N-S equation of the incompressible fluid. Regardless of the form of $G$, we can obtain

$$
\begin{aligned}
\frac{\partial \bar{u}_{i}}{\partial t}+\frac{\partial \bar{u}_{i} u_{j}}{\partial x_{j}} & =-\frac{1}{\rho} \frac{\partial \bar{p}}{\partial x_{i}}+v \frac{\partial^{2} \bar{u}_{i}}{\partial x_{j} \partial x_{j}}, \\
\frac{\partial \bar{u}_{i}}{\partial x_{i}} & =0 .
\end{aligned}
$$

It is set that $\overline{u_{i} u_{j}}=\bar{u}_{i} \bar{u}_{j}+\left(\overline{u_{i} u_{j}}-\bar{u}_{i} \bar{u}_{j}\right), \bar{\tau}_{i j}=-\left(\overline{u_{i} u_{j}}-\bar{u}_{i} \bar{u}_{j}\right)$, so Formula (2) can be changed into

$$
\frac{\partial \bar{u}_{i}}{\partial t}+\frac{\partial \bar{u}_{i} \bar{u}_{j}}{\partial x_{j}}=-\frac{1}{\rho} \frac{\partial \bar{p}}{\partial x_{i}}+v \frac{\partial^{2} \bar{u}_{i}}{\partial x_{j} \partial x_{j}}+\frac{\partial \bar{\tau}_{i j}}{\partial x_{j}} .
$$

The subgrid scale Reynolds stress is an unknown quantity needing to be modeled. It is assumed that

$$
u_{j}^{\prime}=u_{j}-\bar{u}_{j} \text {. }
$$

Formula (5) denotes the small-scale motion. The speed resolution formula is substituted into the expression of the subgrid scale Reynolds stress, so

$$
\bar{\tau}_{i j}=\left(\bar{u}_{i} \bar{u}_{j}-\overline{\bar{u}}_{i} \bar{u}_{j}\right)-\left(\overline{\bar{u}_{i} u_{j}^{\prime}}+\overline{u_{j}^{\prime} \bar{u}_{j}}\right)-\overline{u_{i}^{\prime} u_{j}^{\prime}} .
$$

In the above equations, $x$ is the space position, $t$ is the computational time, $x_{i}$ is the coordinate in the $i$ 


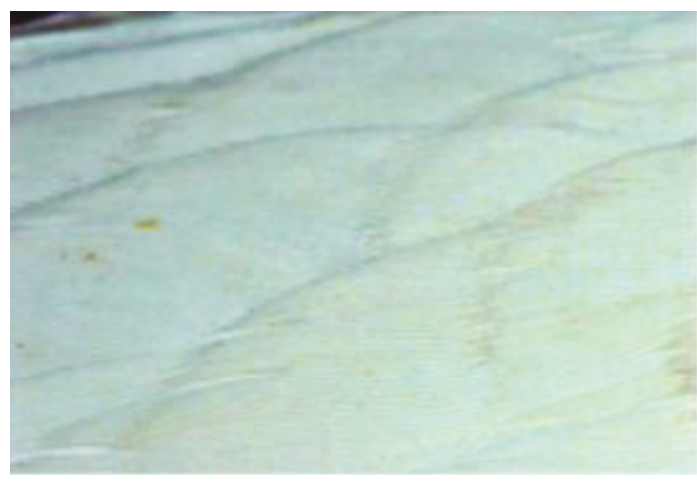

(a) Curved lines on feather edge

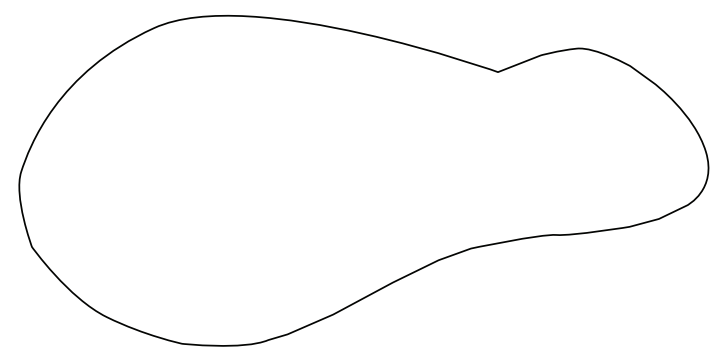

(b) Cross-section of bionic asymmetric rod

FIgURE 1: Asymmetric rod imitating feather edge of carrier pigeon.

direction, $u_{i}$ is the velocity in the $i$ direction, $x_{j}$ is the coordinate in the $j$ direction, $u_{j}$ is the velocity in the $j$ direction, $x^{\prime}$ is the derivative, $\rho$ is the density, $p$ is the pressure, $\tau_{i j}$ is the subgrid scale Reynolds stress, and $v$ is the turbulent viscosity coefficient. In the equation, the first item denotes the Leonard item, namely, the interaction between two large eddies, which can generate small-scale turbulence. The second item is a crossover item which represents the interaction between large and small eddies, wherein the energy between them can be transmitted from large eddies to small eddies. It can also be transmitted reversely from small eddies to large eddies. However, as an average whole, the energy is mainly transferred from large eddies to small eddies. The third item is the antiscatting item, representing the interaction between small eddies, which can generate large eddies and lead to the transmission of energy from small eddies to large eddies.

\section{Flow Noise of Bionic Asymmetric Cross-Section Rod}

3.1. Model of Bionic Asymmetric Cross-Section Rod. A carrier pigeon is a kind of flying animal. Its flying speed can reach up to $177 \mathrm{~km} / \mathrm{h}$ [21-24]. In general, a carrier pigeon flies at $80 \mathrm{~km} / \mathrm{h}$. This speed is roughly equivalent to 75 times the length of the pigeon per second. A carrier pigeon has a streamline body, strong wings, and soft feather. For these characteristics, they can fly freely in the air. Carrier pigeons can fly far very quickly, indicating that they can effectively solve the problem of energy saving and resistance reduction in air medium motion. This is closely correlated with the unique surface appearance and special forms of feather surface. The diethyl ether solution was used to narcotize an experimental carrier pigeon. The epidermis with a feather was taken out from the back of the carrier pigeon. The epidermis was spread and fixed on a plane with the same size of the epidermis. Here, a specimen was made. Planar image collection was conducted to the specimen. As for the collection method, images were shot by a digital camera at first. Then, different multiples of images of the specimen

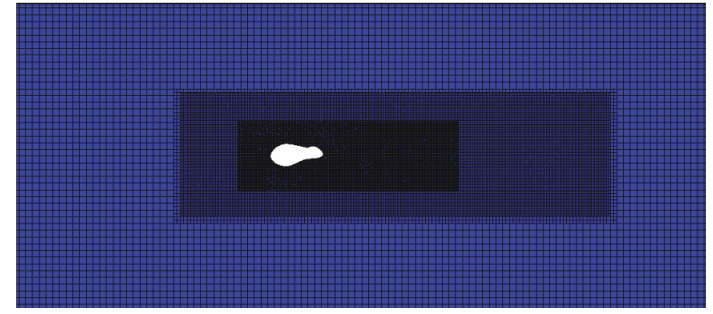

FIgURE 2: Computation domain model of asymmetric crosssection rod.

were collected under the microscope. Finally, the surface appearance image of the carrier pigeon can be obtained, as shown in Figure 1(a). Each feather presents a surface structure which is formed through tile-tail covering from outside to inside. The root of each feather is covered by the tail end of the feather of the previous row. They are arranged in a staggered manner. The overlaid arrangement between feathers forms a curved groove structure and an overlaid curved edge line structure. The curvature of the curved groove and the curved edge line is the same with that of feather edges. King and Pfizenmaier [25] conducted aerodynamic noise testing of rods with different cross-section shapes, finding that the aerodynamic noise of the oval cross-section rod was lower than that of other cross-section rods. In combination with feather edge curved lines in Figure 1(a), the bionic asymmetric cross-section was established, as shown in Figure 1(b). As a whole, the rod cross-section is approximate to an oval structure.

\subsection{Flow Fields of Bionic Asymmetric Cross-Section Rod.} Based on the asymmetric cross-section rod in Figure 1(a), a three-dimensional model was made through stretching. After that, a computation domain model of the bionic asymmetric rod was established, and mesh division was conducted, as shown in Figure 2. In order to fully distinguish flowing in the boundary layer, meshes around special rods were densified. After steady numerical simulation, the $Y+$ value of cylindrical near-wall face meshes was generated. Whether the viscous sublayer in the boundary layer can be distinguished through mesh densifying was checked. Turbulence 


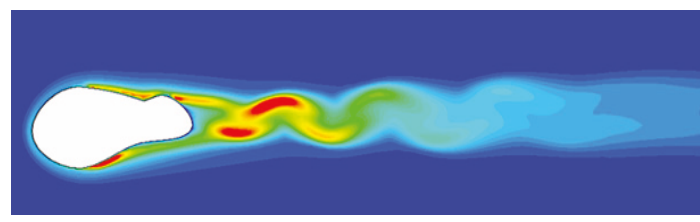

(a) Distribution of turbulence energy

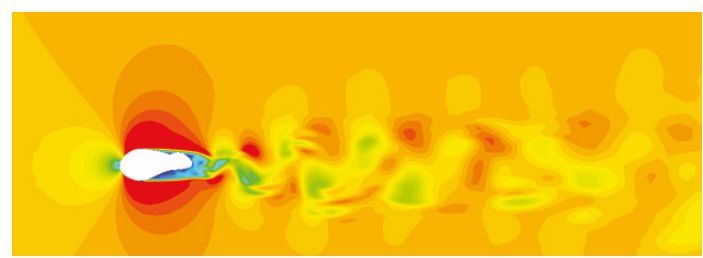

(b) Distribution of speed field

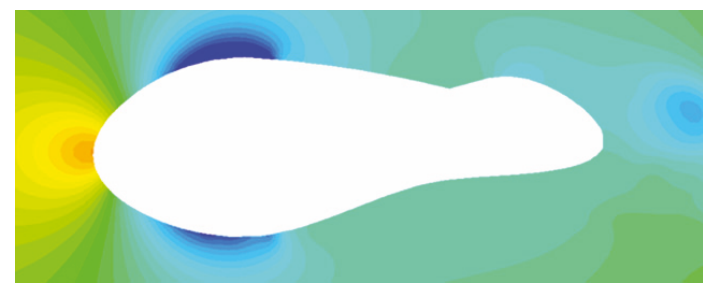

(c) Distribution of pressure field

Figure 3: Flow field distribution of asymmetric cross-section rod.

length in the flow field turbulence area was reported. Whether turbulence motion can be captured by the meshes was verified. In the paper, the $Y+$ value of the computed near-wall meshes was far lower than 1 , so the boundary layer mesh was able to capture flowing in the boundary layer. The end near the rod part was set as the entrance. The end far from the rod part was set as the exit. As for the entrance condition, the entrance speed was $30 \mathrm{~m} / \mathrm{s}$, while the exit was the pressure exist. Wall faces were set as boundary conditions between the entrance and the exit. The asymmetric rod wall face was set as the nonslippage wall face. Other wall faces were set as slippage wall faces. The distribution of turbulence energy, distribution of speed field, and distribution of pressure field of the asymmetric cross rod were computed. Results are shown in Figure 3. It is shown in Figure 3(a) that the thickness of the boundary layer on the lower side of the rod was obviously larger than that of the upper side. Unsteady flow separation caused by the asymmetric crosssection rod is a type of inevitable complicated flow phenomenon. Due to flow separation, eddies near the rod surface will be continuously transported to wake flows, so large-scale eddies will be formed. These eddies get shed continuously from the rod part and flow to the downstream parts. Meanwhile, new eddies are formed continuously. In addition, eddies on the upper side and lower side of the asymmetric cross-section rod are divided into two strands of eddies with opposite rotation directions in the wake flow area. It is shown in Figure 3(b) that a series of small eddies were formed in wake flow areas of the asymmetric cross-section rod. Speeds on upper and lower sides of the rod were big, so obvious negative pressure areas were formed on the upper and lower sides of the rod, as shown in Figure 3(c).

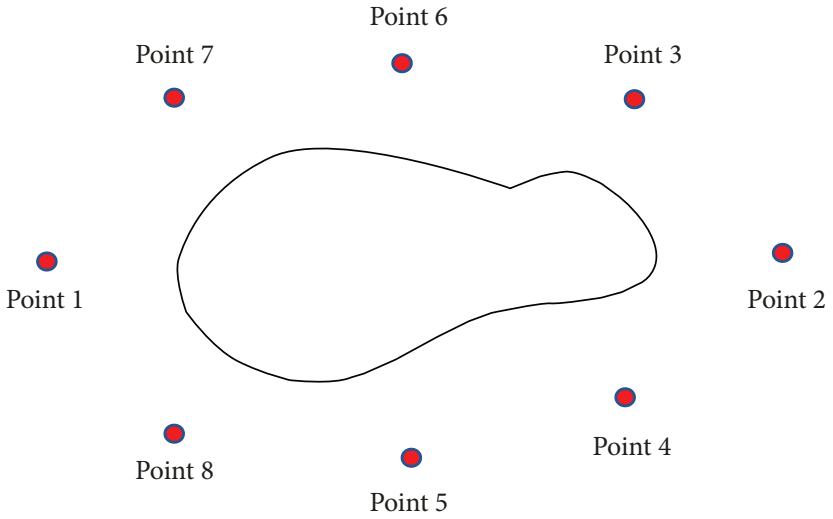

FIGURE 4: Observation points of optimized asymmetric crosssection rod.

3.3. Flow Noise of Bionic Asymmetric Cross-Section Rod. The pantograph does not have a sealed curved face. Hence, the indirect boundary element method was used in the computation [26-29]. Acoustic computation meshes on the pantograph surface are triangular meshes, with the edge length of $11.5 \mathrm{~mm}$. Hence, the maximum computation frequency can reach $5000 \mathrm{~Hz}$. The total number of computation nodes is 38,022 . Air density is $1.225 \mathrm{~kg} / \mathrm{m}^{3}$. Sound speed is $340 \mathrm{~m} / \mathrm{s}$. The damping effect of air on acoustic propagation was not taken into account. It is assumed that the symmetric planes of ground and mirror image are fully reflecting surfaces of sound waves. During computation, the only existence of dipole sound sources on the surface was taken into account. Namely, only the surface pulsation pressures were loaded to superficial acoustic computation meshes as boundary conditions of boundary element computation. Eight observation points were arranged at positions $1 \mathrm{~m}$ away from the asymmetric cross-section rod, as shown in Figure 4. In this way, radiation noise on the upper, lower, left, and right parts of the asymmetric cross-section rod can be reflected. Sound pressure levels of all the observation points were extracted, as shown in Figure 5. It is shown in the diagram that the sound pressure level curve of each observation point had a peak around $1000 \mathrm{~Hz}$ because of interaction results between the local characteristics of the structures and sound wave, while the energy of radiation noise was mainly centralized within $1000 \mathrm{~Hz}$. When the frequency was over $1000 \mathrm{~Hz}$, the sound pressure level was gradually decreased with the increase of the analyzed frequency until the stable state was reached. The reason is that with the increase of the analyzed frequency, the wavelength of sound wave will be decreased, and the interaction between the local characteristics of the structures and sound wave will be weakened. The sound pressure level curve of observation point 2 was different from those of other observation points. Within the frequency band exceeding $2000 \mathrm{~Hz}$, periodic fluctuation appeared mainly because the observation point was located in the wake flow area of the asymmetric cross-section rod, while these eddies got shed continuously from the rod and flowed to the wake flow area. Meanwhile, new eddies formed continuously. The total noise of each observation was computed. Results were $87.2 \mathrm{~dB}, 81.8 \mathrm{~dB}, 78.4 \mathrm{~dB}, 76.0 \mathrm{~dB}$, 


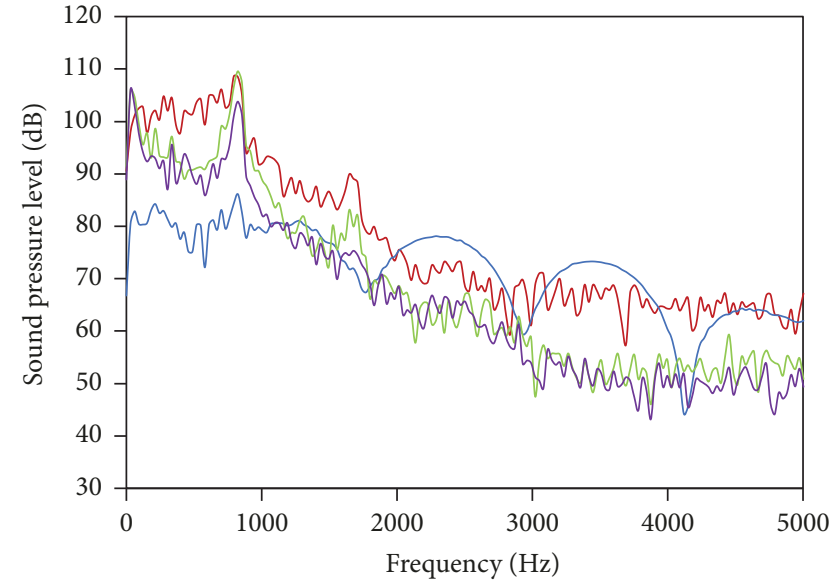

$\begin{array}{ll}\text { Observation point } 1 & \text { Observation point } 3 \\ \text { Observation point } 2 & \text { Observation point } 4\end{array}$

(a) Observation points $1,2,3$, and 4

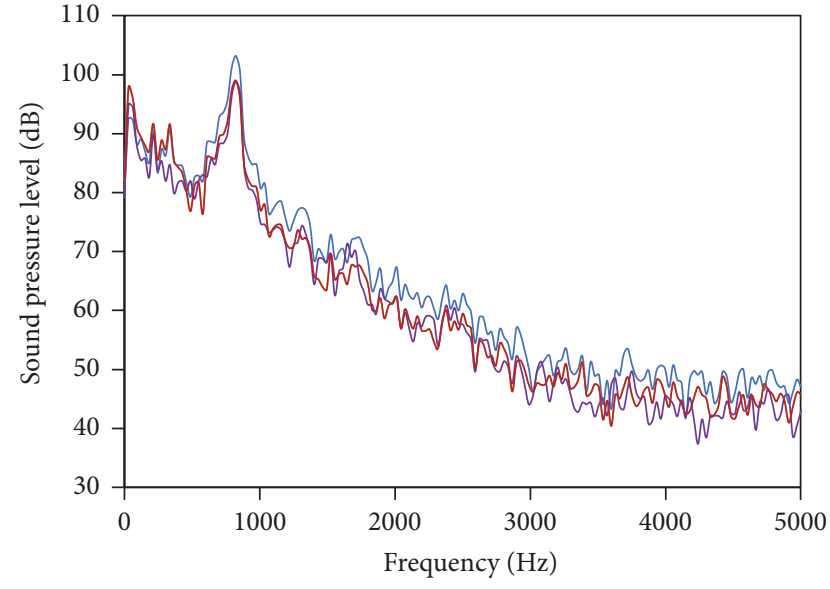

$\begin{array}{lll}\text { Observation point } 5 & - & \text { Observation point } 7 \\ \text { Observation point } 6 & - & \text { Observation point } 8\end{array}$

(b) Observation points $5,6,7$, and 8

Figure 5: Sound pressure levels of observation points of asymmetric cross-section rod.

$73.3 \mathrm{~dB}, 70.3 \mathrm{~dB}, 69.4 \mathrm{~dB}$, and $70.3 \mathrm{~dB}$. Obviously, the total radiation noise of observation point 1 was obviously larger than those of other observation points. Hence, observation point 1 was located at the front end of the asymmetric cross-section rod. This position was not influenced by structural flow fields, while the energy here was relatively strong. The contour of the radiation noise of the asymmetric cross-section rod was further extracted. Results are shown in Figure 6. It is shown in the diagram that the radiation noise of the asymmetric cross-section rod was similar to a monopole noise source. Radiation noise on the upper side was obviously larger than that on the lower side, which conformed to the sound pressure level curve in Figure 5.

\section{Flow Noise of Optimized Bionic Asymmetric Cross-Section Rod}

4.1. Flow Field of Optimized Bionic Asymmetric Cross-Section Rod. The above acoustic computation results show that the radiation noise of the bionic asymmetric cross-section rod was large. Hence, it is necessary to make the reshaping design of it. Based on the original model in Figure 7(a), raised and bionic curved line structures were added. Then, the optimized bionic asymmetric cross-section rod was obtained, as shown in Figure 7(b).

According to computation domain sites of the original model, the computation domain of the optimized model was designed, while meshes were divided, as shown in Figure 8 . The turbulence energy distribution, speed distribution, and pressure field distribution of the optimized model were computed, as shown in Figure 9. In comparison with the turbulence energy of the original model, it is found in Figure 9 (a) that shedding of wake flow eddies of the optimized model was effectively controlled. Alternate shedding of eddies was not found in flow fields near the rod. Eddies in the wake flow areas were changed from two strands to one strand, while the energy was relatively centralized. It is found through the comparison of Figures 3(b) and 9(b) that the speed fields were distributed continuously in the wake flow area of the optimized model, while speed fields in the wake flow areas of the original model were dispersed. It is found through the comparison of Figures 3(c) and 9(c) that the area of the negative pressure area on the upper side of the optimized model was reduced obviously.

4.2. Flow Noise of Optimized Bionic Asymmetric CrossSection Rod. As well, the sound pressure level of each observation point of the optimized model was computed and compared with the original model. Results are shown in Figure 10. It is shown in the diagram that the radiation noise of both models gradually increased with the increase of analysis frequency at first and then gradually decreased to a stable value. The original model had obvious peak noise around $1000 \mathrm{~Hz}$, while the optimized model had obvious peak noise around $100 \mathrm{~Hz}$. In addition, the optimized model could effectively reduce the radiation noise of each observation point. Especially above $3000 \mathrm{~Hz}$, the high-frequency noise reduction effect was obvious. At observation point 2, noise reduction effects of the optimized model were especially obvious. The reason is that the observation point was located on the rear edge of the lower side of the asymmetric cross-section rod. In comparison with the original model, the thickness of the boundary layer on the rear edge of the lower side of the optimized model was reduced, while stability flowing in the boundary layer decreased, so noise reduction effects were obvious. In addition, the rear edge of the lower side had a raised structure which could reduce speed gradient and the negative pressure area, so the noise reduction effect was obvious. It could also be found in Figure 10 that in some frequency bands, the radiation noise of the optimized model was larger than that of the original model. Hence, the total noise of these two models was 


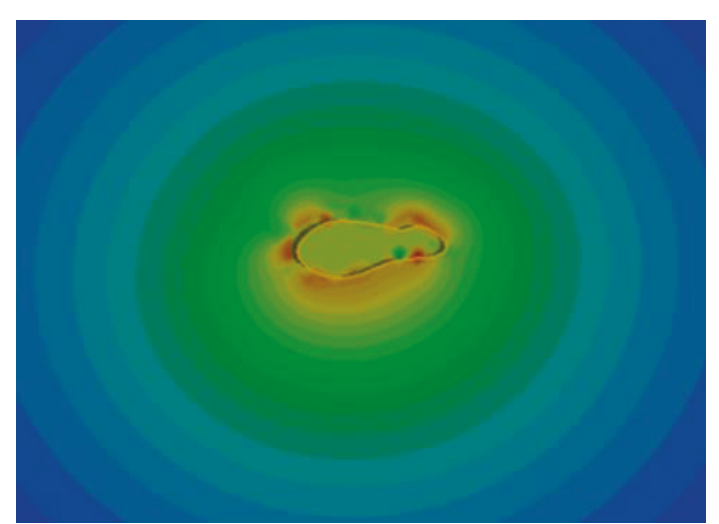

(a) $100 \mathrm{~Hz}$

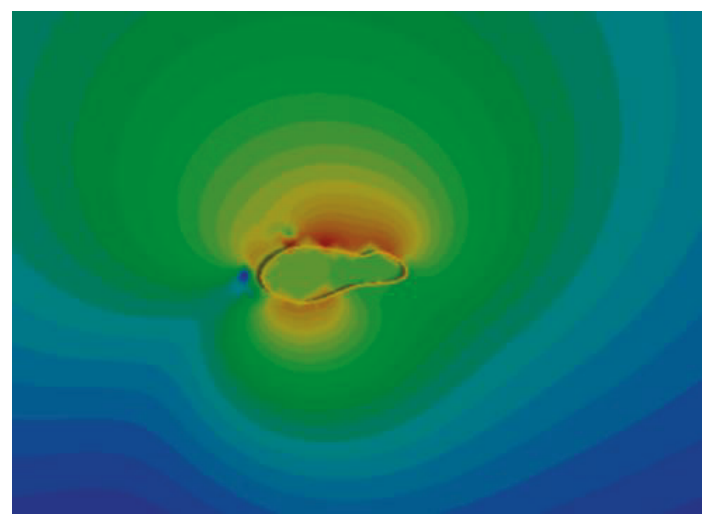

(c) $2000 \mathrm{~Hz}$

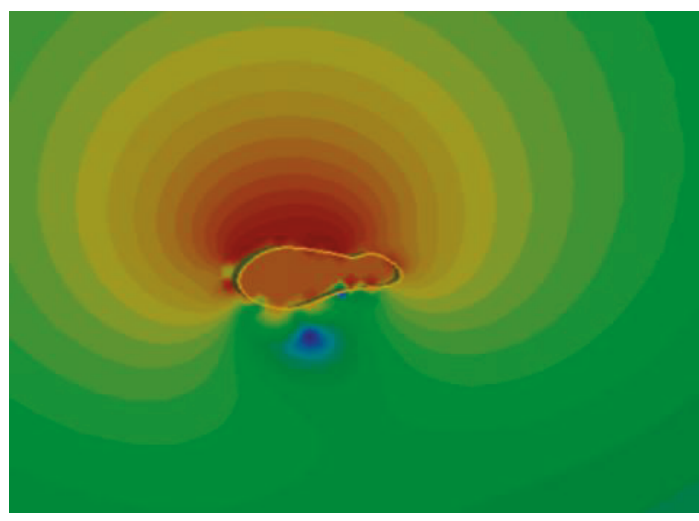

(e) $4000 \mathrm{~Hz}$

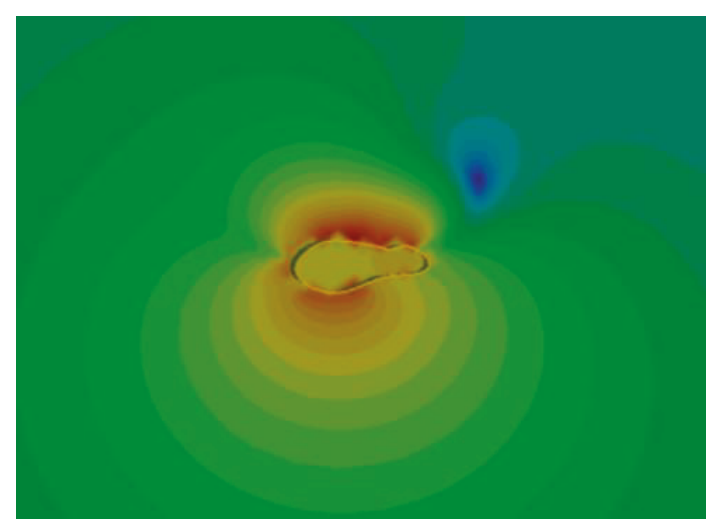

(b) $1000 \mathrm{~Hz}$

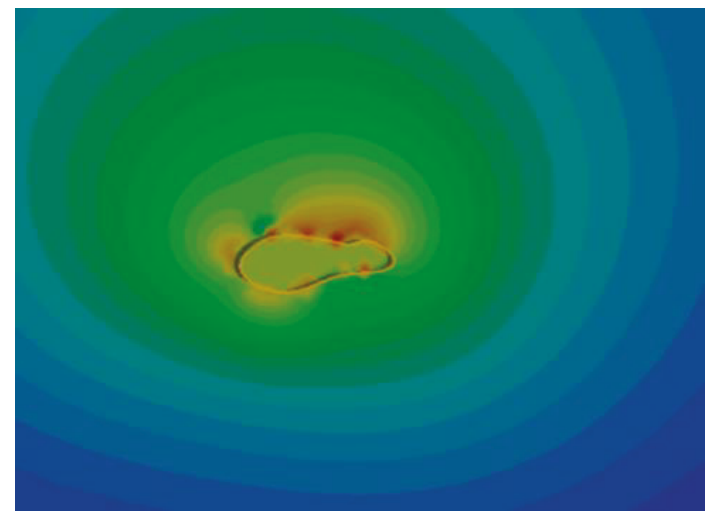

(d) $3000 \mathrm{~Hz}$

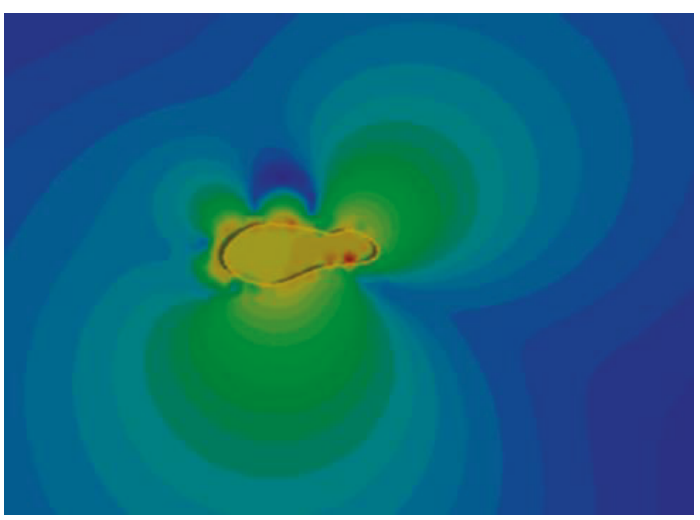

(f) $5000 \mathrm{~Hz}$

Figure 6: Contour of radiation noise of asymmetric cross-section rod.

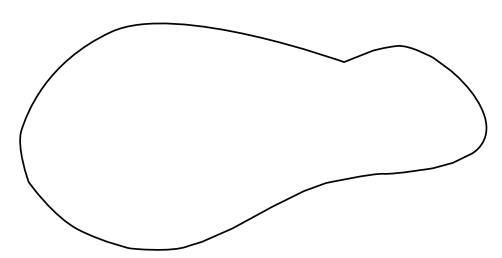

(a) Original model

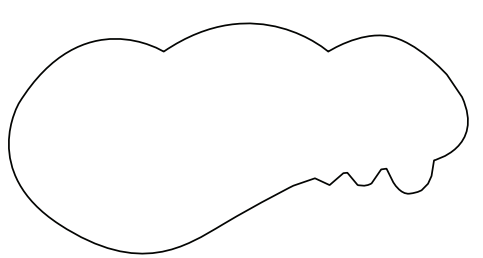

(b) Optimized model

FIGURE 7: Original and optimized asymmetric cross-section rod.

computed. Results are shown in Figure 11. It is shown in the diagram that in comparison with the original model, the total noise of the optimized model at each observation point was obviously improved because the bionic structure can reduce the interaction between the local structure and sound wave. Especially at observation point 2, the total noise decreased 


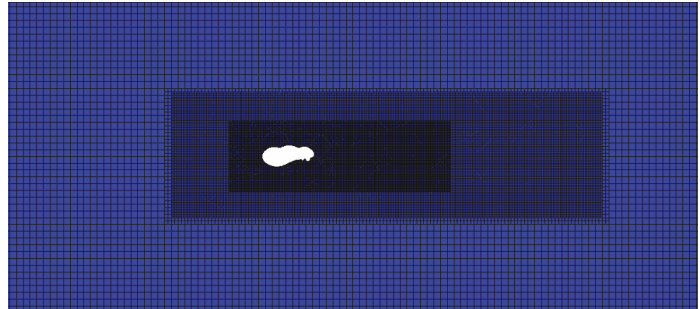

FIGURE 8: Optimized computation model of asymmetric crosssection rod.

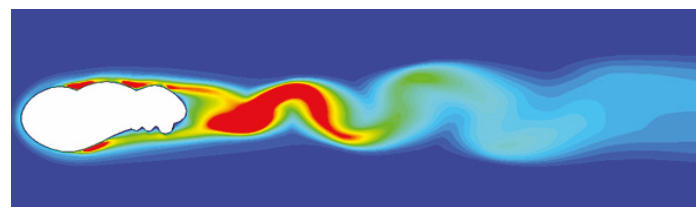

(a) Distribution of turbulence energy

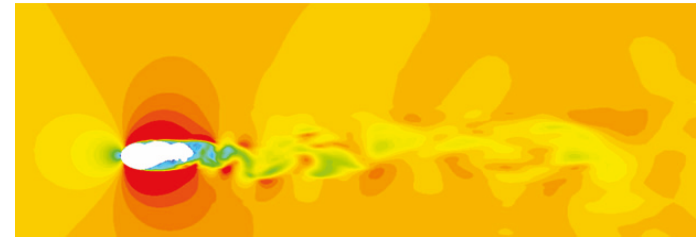

(b) Distribution of speed field

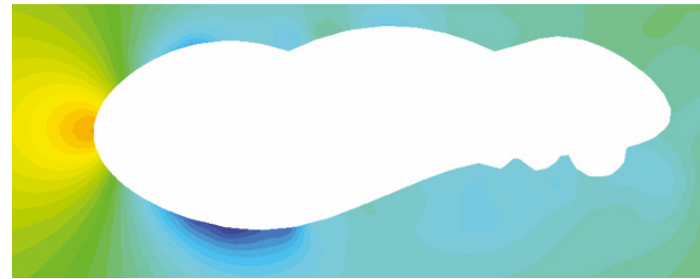

(c) Distribution of pressure field

FIGURE 9: Flow field distribution of optimized asymmetric crosssection rod.

by $10 \mathrm{~dB}$. In addition, observation point 1 was still the observation point with the maximum radiation noise among these two models.

\section{Flow Noise of Optimized Pantograph}

5.1. Flow Field of Optimized Pantograph. Numerical simulation analysis results of the aerodynamic noise of the rod show that the bionic improved structure can effectively control rod turbulence, so as to reduce the aerodynamic noise of the rod. The paper further explores the engineering application of the aerodynamic noise bionic control technology of rods. Through numerical simulation, the paper researches control effects of the rod bionic flow control method in the aerodynamic noise of a high-speed train pantograph. A pantograph was selected as the research object. According to the idea of noise reduction control with bionic flowing, the bionic lownoise improvement design was conducted. Before low-noise improvement, it is necessary to know the positions of the main aerodynamic noise sources of the pantograph model and then the parts with the most obvious aerodynamic noise can be improved. Research results in $[15,20]$ show that the head of the pantograph is the major noise source of the whole structure. Hence, the bionic rod was applied to the pantograph head, and a bionic pantograph structure was obtained, as shown in Figure 12.

As for the computation of the pantograph model, the inflowing speed was $300 \mathrm{~km} / \mathrm{h}$, while the Mach number was 0.24 , which was lower than 0.3 . Hence, the air compressibility can be neglected. As for aerodynamic noise with low-Mach $(\mathrm{Ma}<3)$ flowing, feedback effects of the sound field on the flow field can be neglected. Meanwhile, the contribution amount of the turbulence quadrupole sound source to the sound field can be neglected in comparison with the dipole noise source. Hence, the dipole aerodynamic noise of the pantograph model can be predicted by computational fluid mechanism and computation acoustic distribution. The computation domain of the pantograph is a cuboid with a length of $8 \mathrm{~m}$, a width of $4 \mathrm{~m}$, and a height of $3 \mathrm{~m}$. The pantograph was placed on the lower boundary. The flow field entrance of the computation domain was $3.5 \mathrm{~m}$ away from the pantograph model. The flow field exit was $4.5 \mathrm{~m}$ from the pantograph model. The distance between the upper boundary and the lower boundary was $3 \mathrm{~m}$. The distance between the front and rear boundaries and the pantograph model was $2 \mathrm{~m}$. Nonstructural hybrid meshes combining hexahedron and tetrahedron meshes were used as external flow field meshes of the pantograph. The thickness of meshes on the surface boundary layer of the pantograph model was $1 \mathrm{~mm}$, wherein 6 nodes were set in the boundary layer. The minimum mesh size on the model surface was $4 \mathrm{~mm}$, as shown in Figure 13. In order to ensure computation precision, except for the setting of boundary layer meshes, meshes of areas near the pantograph model and meshes of the wake flow areas, which had large flow field changes, were densified. Boundary conditions of the external flow field computation of the pantograph model are the following: flow field entrance is the speed entrance, with the inflowing speed of $300 \mathrm{~km} / \mathrm{h}$; the flow field exist is the pressure exist, with the static pressure at the exit boundary of $0 \mathrm{~Pa}$; front and rear boundaries were set as symmetric boundaries; the surface of the pantograph model was set as smooth and nonslippage wall faces. The air flow rate was under $0.3 \mathrm{Mach}$, so it could be deemed as incompressible flow. Hence, LES was used to solve the N-S equation of the unsteady incompressible fluid. Solution is set as follows: a pressure-based separated solver of hidden type was selected, while a second-order upwind scheme with high stability and accuracy was selected as the dispersion format. Computer time step length was $0.00005 \mathrm{~s}$. Computation was started since the initial state. The resistance coefficient of the pantograph model was monitored. When the resistance coefficient tended to be stable, flowing can be deemed to reach a state of full development. Then, pulsation pressure data of the surface of the pantograph model is then computed and output for acoustic computation.

The turbulence energy distribution, speed field distribution, and pressure field distribution of the pantograph were 


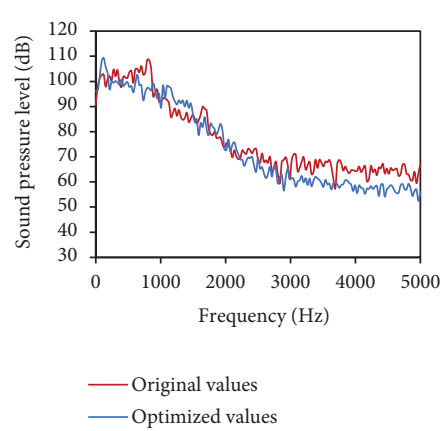

(a) Observation point 1

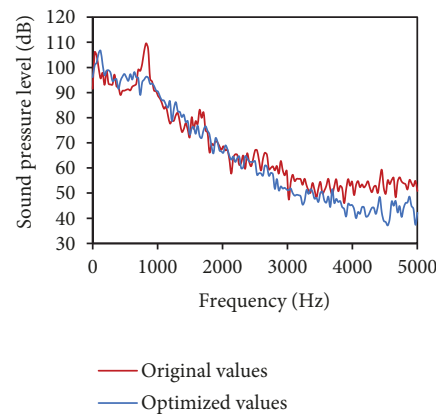

(c) Observation point 3

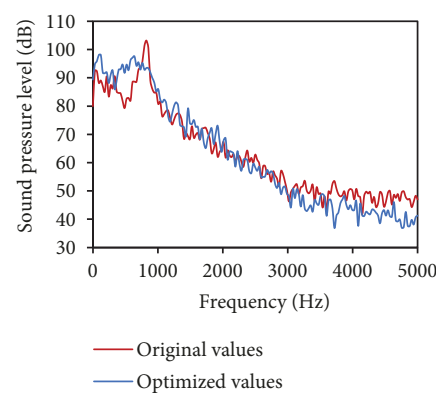

(e) Observation point 5

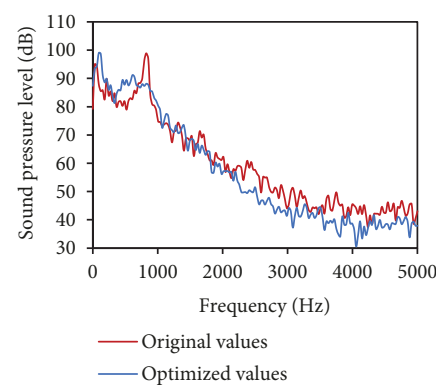

(g) Observation point 7

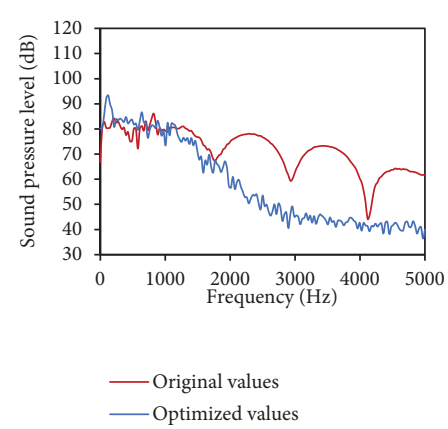

(b) Observation point 2

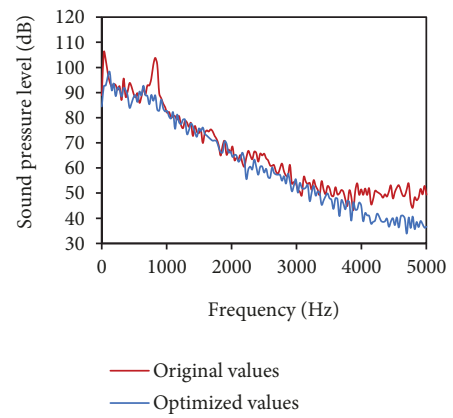

(d) Observation point 4

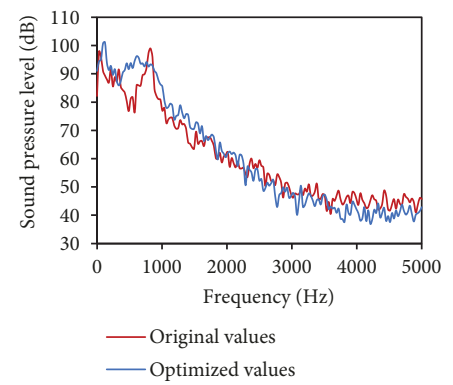

(f) Observation point 6

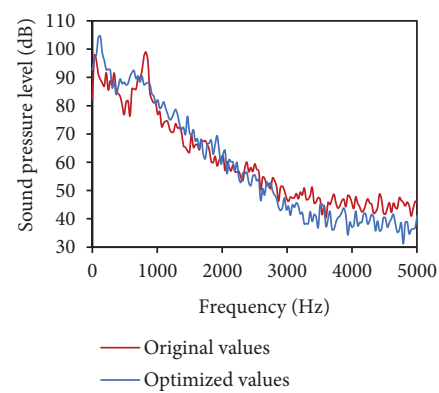

(h) Observation point 8

Figure 10: Comparison of sound pressure levels of observation points before and after optimization.

computed, as shown in Figure 14. The pantograph was mainly composited of various rods. Its external flow fields have very strong unsteady characteristics. Eddy shedding similar to Karman Vortex Street can be observed in wake flow fields of the pantograph. This is because there are many pantograph components; due to eddy interactions generated by each component in the flow field, a complicated wake flow structure was formed. It is shown in Figure 14(a) that areas with high turbulence energy were centralized supporting base and head of the pantograph as well as hinged joints of the upper frame and the lower arm rod. It is shown in Figure 14(b) that areas with high flow rates were also centralized at the supporting base and head of the pantograph as well as hinged joints of the upper frame and lower arm rod. A long low-speed area would be formed in the wake flow area of the pantograph head. Fluid speeds were high at the 


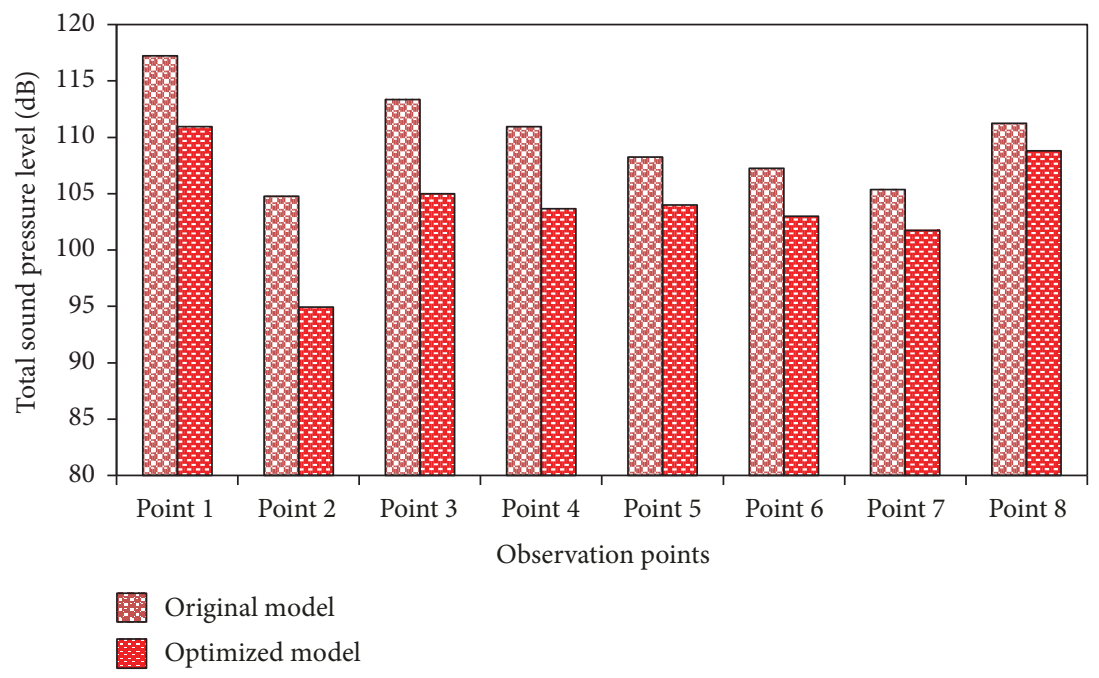

FIGURE 11: Comparison of total noise of observation points before and after optimization.

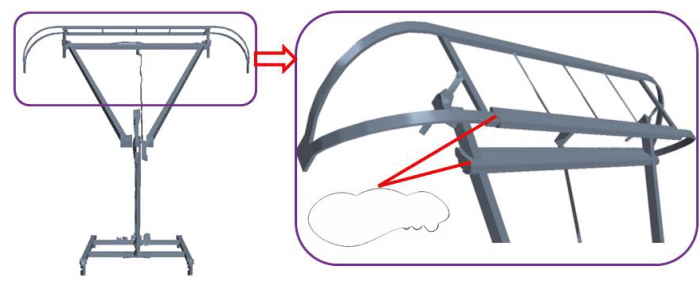

Figure 12: Improved geometric model of pantograph.

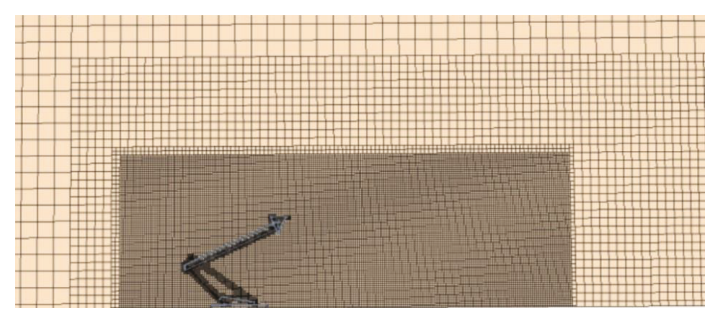

FIGURE 13: Computation model of improved pantograph.

supporting base and pantograph head as well as hinged joints of the upper frame and lower arm rod, so negative pressure areas were formed here, as shown in Figure 14(c). In addition, it can be found that large negative pressure areas were formed at rear parts of the pantograph head, while obvious positive pressure areas existed at the front rod. Hence, large radiation noise would be generated at the pantograph head due to interactions between positive pressures and negative pressures.

5.2. Flow Noise of Optimized Pantograph. According to flow field results, the radiation noise of the pantograph was computed. Eight observation points were arranged at the front part, middle part, and rear part of the pantograph, as shown in Figure 15. Sound pressure level curves of all the observation points were extracted, as shown in Figure 16. It is shown in the diagram that the acoustic energy of the

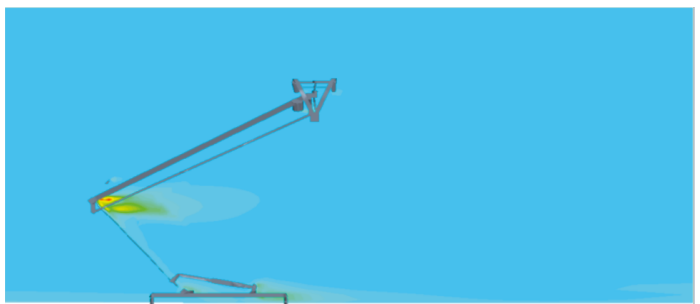

(a) Distribution of turbulence energy

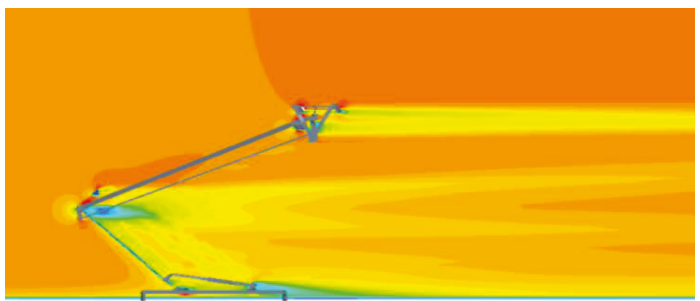

(b) Distribution of speed field

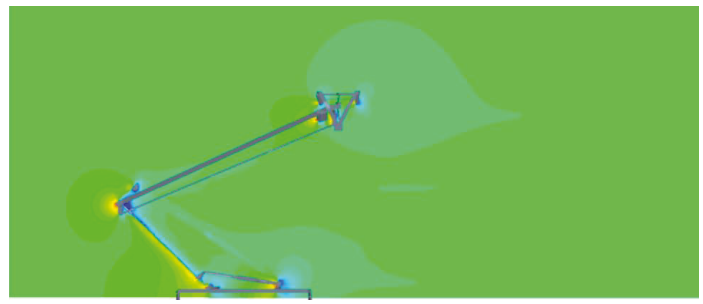

(c) Distribution of pressure field

FIgURE 14: Distribution of flow fields of improved pantograph.

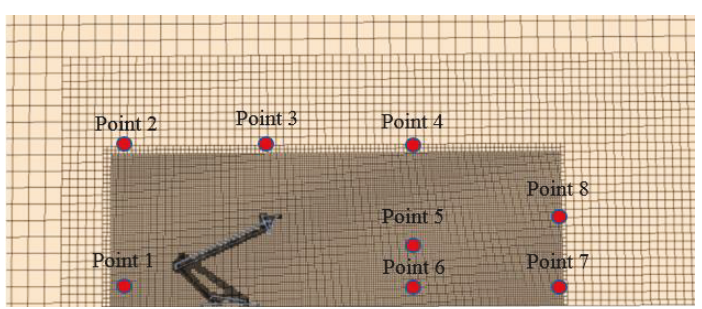

FIGURE 15: Observation points of improved pantograph. 


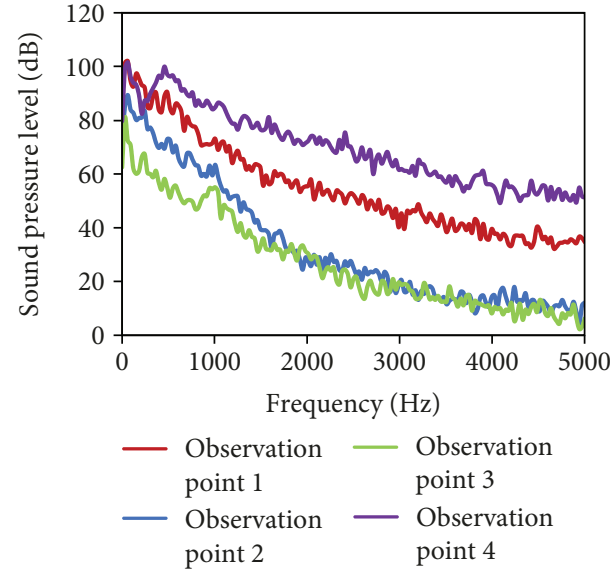

(a) Observation points 1, 2, 3, and 4

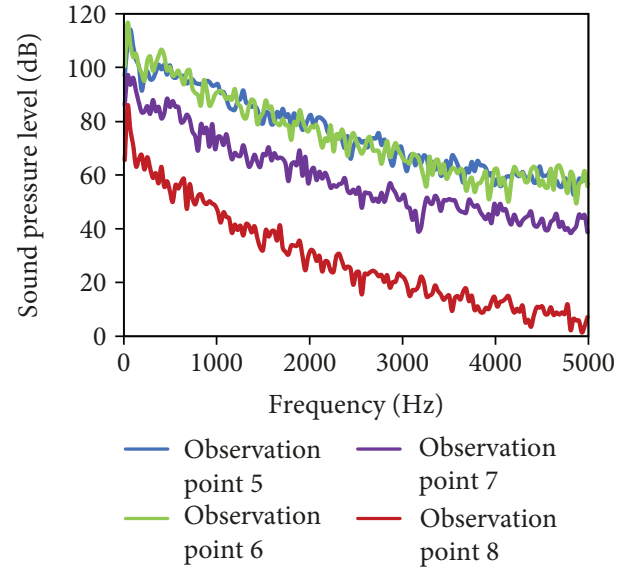

(b) Observation points 5, 6, 7, and 8

FIGURE 16: Sound pressure levels of observation points of improved pantograph.

pantograph was mainly centralized within $700 \mathrm{~Hz}$, while the sound pressure level of the pantograph gradually decreased with the increase of analysis frequency. Observation point 5 and observation point 6 had the maximum noise as these two observation points were located in wake flow areas of the pantograph, while their flow fields were influenced by both the hinges and the base. Hence, the flow fields were complicated, and obvious radiation noise was generated. Sound pressure levels of observation point 3 and observation point 4 were similar, while their values were small. Observation points 8 and 7 were located on the same vertical face, but the noise of observation point 7 was obviously larger than that of observation point 8 as observation point 7 was located behind the pantograph. It was influenced by the pantograph head, hinges, and base rod. Observation point 8 was located above the rear part of the pantograph, so it was less influenced by the disturbance effect of the pantograph rod. The radiation noise contour of the pantograph was extracted, as shown in Figure 17. The aerodynamic noise of the pantograph model was mainly caused by eddy shedding. It suffered the most airflow disturbance caused by pantograph head, hinges, and base. These shed eddies brought away a lot of energy. It was specifically shown by the corresponding pulsation pressures acting on the surface of the pantograph model. These parts had the maximum pulsation pressure. Hence, the most obvious aerodynamic noise appeared here. As shown in Figure 17, the pantograph head was an obvious aerodynamic noise source. In addition, we can also find that the noise of the upper and lower pull rods of the pantograph was low as effective acting areas of wind loads on these rods were small and their retardation effect to winds was weak.

\section{Conclusions}

The thickness of the boundary layer on the lower side of the rod was obviously larger than that of the upper side. Unsteady flow separation caused by the asymmetric cross-section rod is a type of inevitable complicated flow phenomenon. Due to flow separation, eddies near the rod surface will be continuously transported to wake flows, so large-scale eddies will be formed. These eddies get shed continuously from the rod part and flow to the downstream parts. Meanwhile, new eddies are formed continuously. In addition, eddies on the upper side and lower side of the asymmetric cross-section rod are divided into two strands of eddies with opposite rotation directions in the wake flow area. A series of small eddies were formed in wake flow areas of the asymmetric cross-section rod. Speeds on the upper and lower sides of the rod were big, so obvious negative pressure areas were formed on the upper and lower sides of the rod.

Shedding of wake flow eddies of the optimized model was effectively controlled. Alternate shedding of eddies was not found in flow fields near the rod. Eddies in the wake flow areas were changed from two strands to one strand, while the energy was relatively centralized. The speed fields were distributed continuously in the wake flow area of the optimized model, while speed fields in the wake flow areas of the original model were dispersed. The area of the negative pressure area on the upper side of the optimized model was reduced obviously.

The original model had an obvious peak noise around $1000 \mathrm{~Hz}$, while the optimized model had an obvious peak noise around $100 \mathrm{~Hz}$. In addition, the optimized model could effectively reduce the radiation noise of each observation point. Especially above $3000 \mathrm{~Hz}$, the high-frequency noise reduction effect was obvious. The total noise of the optimized model at each observation point was obviously improved. Especially at observation point 2, the total noise decreased by $10 \mathrm{~dB}$. In addition, observation point 1 was the observation point with the maximum radiation noise among these two models.

The aerodynamic noise of the pantograph model was mainly caused by eddy shedding. It suffered the most airflow disturbance caused by pantograph head, hinges, and base. These shed eddies brought away a lot of energy. It was specifically shown by the corresponding pulsation pressures 


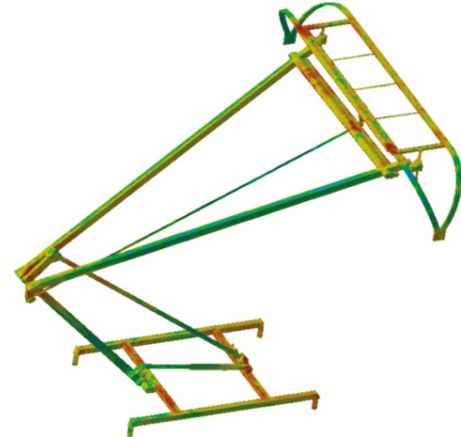

(a) $100 \mathrm{~Hz}$

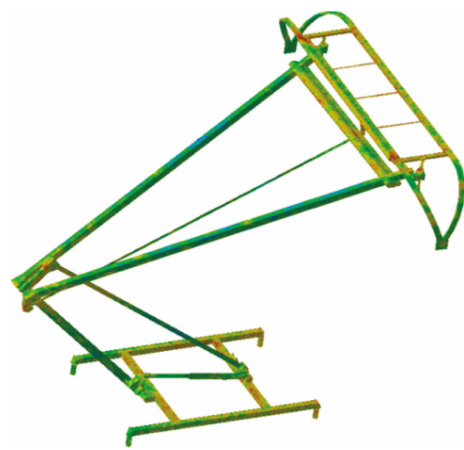

(c) $2000 \mathrm{~Hz}$

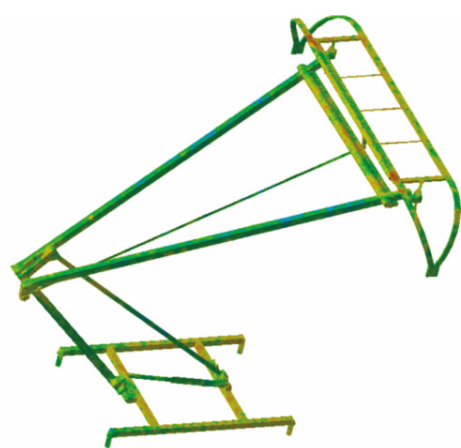

(e) $4000 \mathrm{~Hz}$

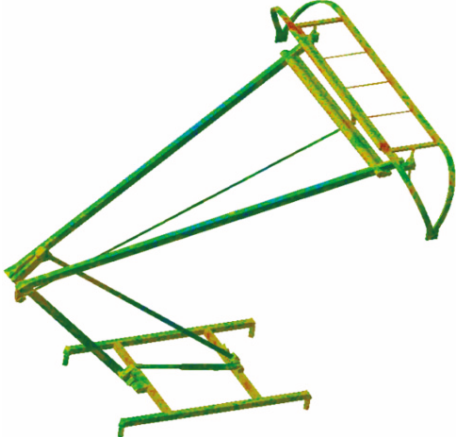

(b) $1000 \mathrm{~Hz}$

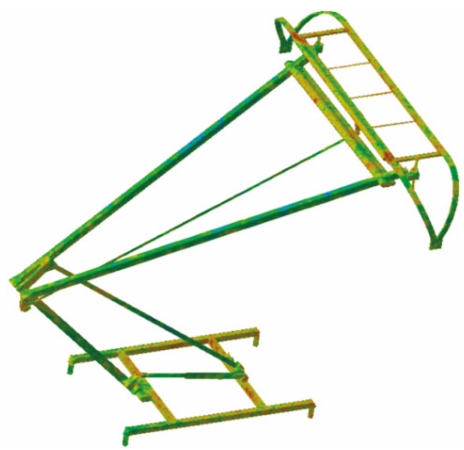

(d) $3000 \mathrm{~Hz}$

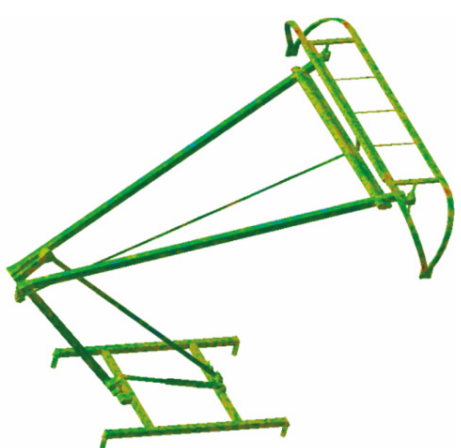

(f) $5000 \mathrm{~Hz}$

FIGURE 17: Radiation noise contour of improved pantograph.

acting on the surface of the pantograph model. These parts had the maximum pulsation pressure. Hence, the most obvious aerodynamic noise appeared here. The pantograph head was an obvious aerodynamic noise source.

\section{Data Availability}

The data used to support the findings of this study are available from the corresponding author upon request.

\section{Conflicts of Interest}

The authors declare that there are no conflicts of interest regarding the publication of this article.

\section{Acknowledgments}

This paper is supported by the National Natural Science Foundation of China (Grant 51705392) and Key Laboratory Scientific Research Project of Shaanxi Education Department (Grant 17JS058).

\section{References}

[1] E. Latorre Iglesias, D. J. Thompson, M. Smith, T. Kitagawa, and N. Yamazaki, "Anechoic wind tunnel tests on high-speed train bogie aerodynamic noise," International Journal of Rail Transportation, vol. 5, no. 2, pp. 87-109, 2017.

[2] W. T. Lu, Y. Wang, and C. Q. Zhang, "Numerical simulation of aerodynamic noises in the far field of the high-speed train with 
considering bogies and connection windshields," Journal of Vibroengineering, vol. 19, no. 3, pp. 2262-2279, 2017.

[3] D. J. Thompson, E. Latorre Iglesias, X. Liu, J. Zhu, and Z. Hu, "Recent developments in the prediction and control of aerodynamic noise from high-speed trains," International Journal of Rail Transportation, vol. 3, no. 3, pp. 119-150, 2015.

[4] X. Zheng, Z. Hao, X. Wang, and J. Mao, "A full-spectrum analysis of high-speed train interior noise under multiphysical-field coupling excitations," Mechanical Systems \& Signal Processing, vol. 75, pp. 525-543, 2016.

[5] Y. D. Zhang, J. Y. Zhang, T. Li, and L. Zhang, "Investigation of the aeroacoustic behavior and aerodynamic noise of a high-speed train pantograph," Science China Technological Sciences, vol. 60, no. 4, pp. 561-575, 2017.

[6] Y. Lee, J. Rho, K. H. Kim, D. H. Lee, and H. B. Kwon, "Experimental studies on the aerodynamic characteristics of a pantograph suitable for a high-speed train," Proceedings of the Institution of Mechanical Engineers, Part F: Journal of Rail and Rapid Transit, vol. 229, no. 2, pp. 136-149, 2015.

[7] L. Zhang, J. Zhang, T. Li, and W. Zhang, "Influence of pantograph fixing position on aerodynamic characteristics of high-speed trains," Journal of Modern Transportation, vol. 25, no. 1, pp. 34-39, 2017.

[8] H. M. Noh, "Noise-source identification of a high-speed train by noise source level analysis," Proceedings of the Institution of Mechanical Engineers, Part F: Journal of Rail and Rapid Transit, vol. 231, no. 6, pp. 717-728, 2017.

[9] E. L. Iglesias, D. J. Thompson, and M. G. Smith, “Componentbased model to predict aerodynamic noise from high-speed train pantographs," Journal of Sound and Vibration, vol. 394, pp. 280-305, 2017.

[10] D. Luo, S. N. Xiao, and G. W. Yang, "Carbon fiber reinforced plastic material of pantograph dome optimized design for reducing noise," Railway Locomotive \& Car, vol. 33, no. S1, pp. 83-86, 2013.

[11] Y. G. Xiao and Y. Shi, "Aerodynamic noise calculation and shape optimization of high-speed train pantograph insulators," Journal of Railway Science and Engineering, vol. 9, no. 6, pp. 72-76, 2012.

[12] W. F. King III, "A précis of developments in the aeroacoustics of fast trains," Journal of Sound and Vibration, vol. 193, no. 1, pp. 349-358, 1996.

[13] C. Noger, J. C. Patrat, J. Peube, and J. L. Peube, “Aeroacoustical study of the TGV pantograph recess," Journal of Sound and Vibration, vol. 231, no. 3, pp. 563-575, 2000.

[14] T. Sueki, M. Ikeda, and T. Takaishi, "Aerodynamic noise reduction using porous materials and their application to high-speed pantographs," Quarterly Report of RTRI, vol. 50, no. 1, pp. 26-31, 2009.

[15] T. Kurita, "Development of external-noise reduction technologies for Shinkansen high-speed trains," Journal of Environment and Engineering, vol. 6, no. 4, pp. 805-819, 2011.

[16] H. H. Yu, J. C. Li, and H. Q. Zhang, "On aerodynamic noises radiated by the pantograph system of high-speed trains," Acta Mechanica Sinica, vol. 29, no. 3, pp. 399-410, 2013.

[17] J. L. Liu, J. Y. Zhang, and W. H. Zhang, "Study on characteristics of unsteady aerodynamic loads of a high-speed train under crosswinds by large eddy simulation," Journal of the China Railway Society, vol. 35, no. 6, pp. 13-20, 2013.
[18] Y. Zhang, J. Zhang, T. Li, L. Zhang, and W. Zhang, "Research on aerodynamic noise reduction for high-speed trains," Shock and Vibration, vol. 2016, Article ID 6031893, 21 pages, 2016.

[19] J. Du, J. Y. Liang, and A. Q. Tian, "Analysis of aeroacoustics characteristics for pantograph of high-speed trains," Journal of Southwest Jiaotong University, vol. 50, no. 5, pp. 935-941, 2015.

[20] J. Lee and W. Cho, "Prediction of low-speed aerodynamic load and aeroacoustic noise around simplified panhead section model," Proceedings of the Institution of Mechanical Engineers, Part F: Journal of Rail and Rapid Transit, vol. 222, no. 4, pp. 423-431, 2008.

[21] A. M. Berg and A. A. Biewener, "Wing and body kinematics of takeoff and landing flight in the pigeon (Columba livia)," Journal of Experimental Biology, vol. 213, no. 10, pp. 16511658, 2010.

[22] I. G. Ros, M. A. Badger, A. N. Pierson, L. C. Bassman, and A. A. Biewener, "Pigeons produce aerodynamic torques through changes in wing trajectory during low speed aerial turns," Journal of Experimental Biology, vol. 218, no. 3, pp. 480-490, 2015.

[23] Q. Xue and D. Haibin, "Aerodynamic parameter identification of hypersonic vehicle via pigeon-inspired optimization," Aircraft Engineering and Aerospace Technology, vol. 89, no. 3, pp. 425-433, 2017.

[24] Q. Wei, S. Zhong, and X. Huang, "Experimental evaluation of flow-induced noise in level flight of the pigeon (Columba livia)," The Journal of the Acoustical Society of America, vol. 134, no. 1, pp. EL57-EL63, 2013.

[25] W. F. King and E. Pfizenmaier, "An experimental study of sound generated by flows around cylinders of different crosssection," Journal of Sound and Vibration, vol. 328, no. 3, pp. 318-337, 2009.

[26] S. Park, W. Kim, and S. I. Kim, "A numerical prediction model for vibration and noise of axial flux motors," IEEE Transactions on Industrial Electronics, vol. 61, no. 10, pp. 5757-5762, 2014.

[27] J. Liu and D. W. Herrin, "Enhancing micro-perforated panel attenuation by partitioning the adjoining cavity," Applied Acoustics, vol. 71, no. 2, pp. 120-127, 2010.

[28] J. M. Kim, B. K. Jung, S. J. Heo, S. J. Ahn, and W. B. Jeong, "Analysis of sources and contribution for the radiated noise of drum-type washing machine," Transactions of the Korean Society for Noise and Vibration Engineering, vol. 24, no. 8, pp. 628-635, 2014.

[29] F. L. M. Dos Santos, J. Anthonis, F. Naclerio, J. J. C. Gyselinck, H. Van der Auweraer, and L. C. S. Goes, "Multiphysics NVH modeling: simulation of a switched reluctance motor for an electric vehicle," IEEE Transactions on Industrial Electronics, vol. 61, no. 1, pp. 469-476, 2014. 


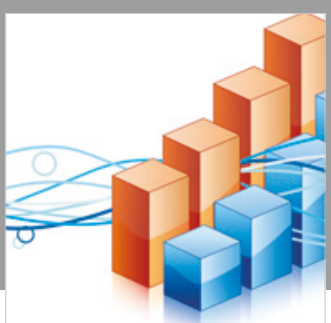

Advances in

Operations Research

\section{-n-m}
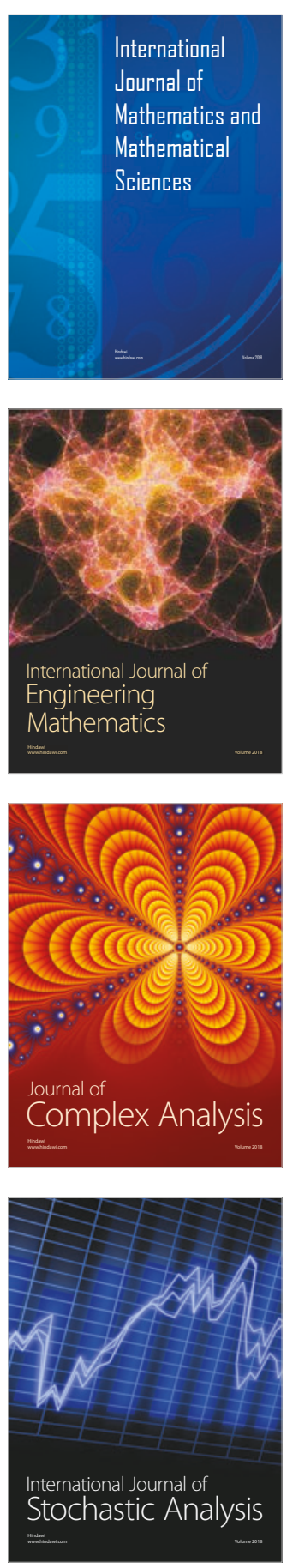
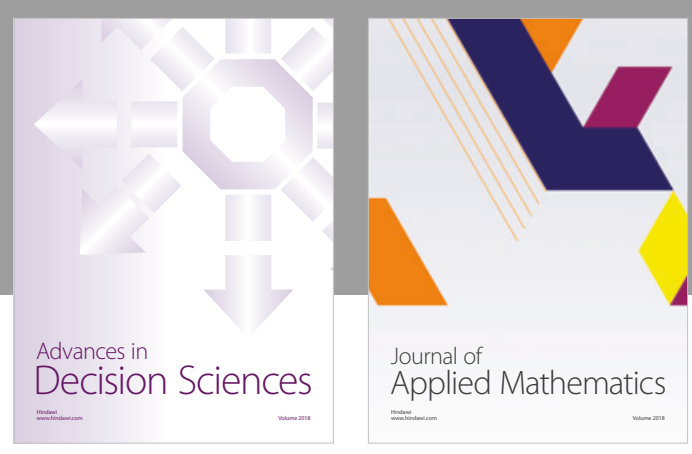

Journal of

Applied Mathematics
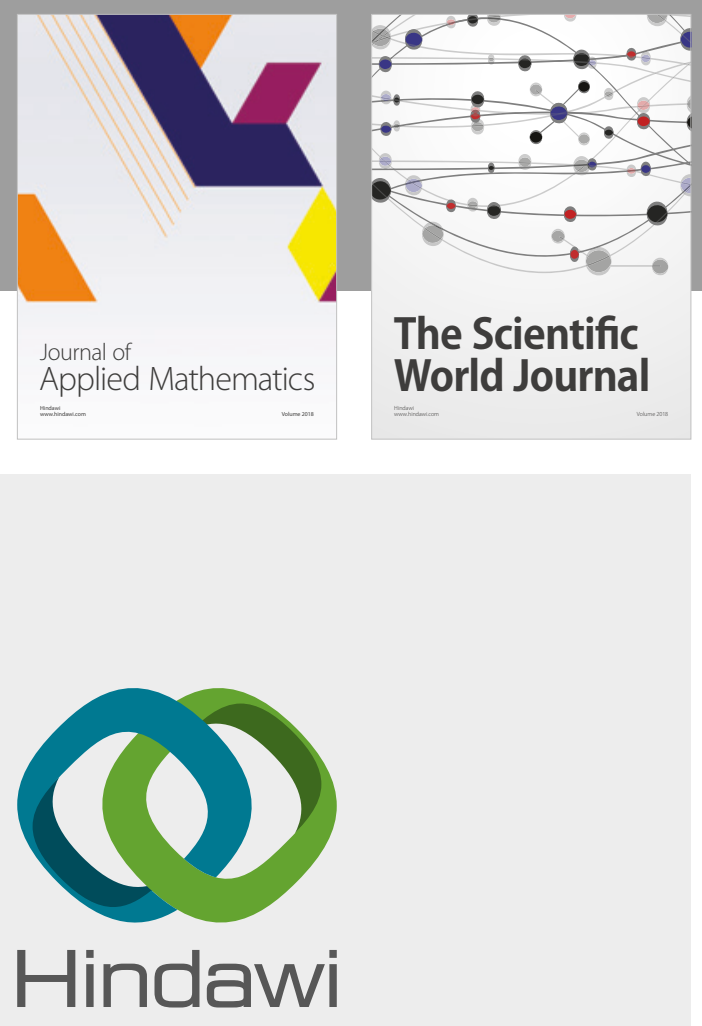

Submit your manuscripts at

www.hindawi.com

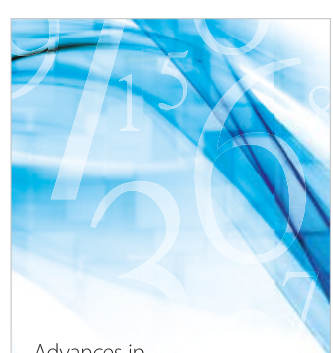

Advances in
Numerical Analysis
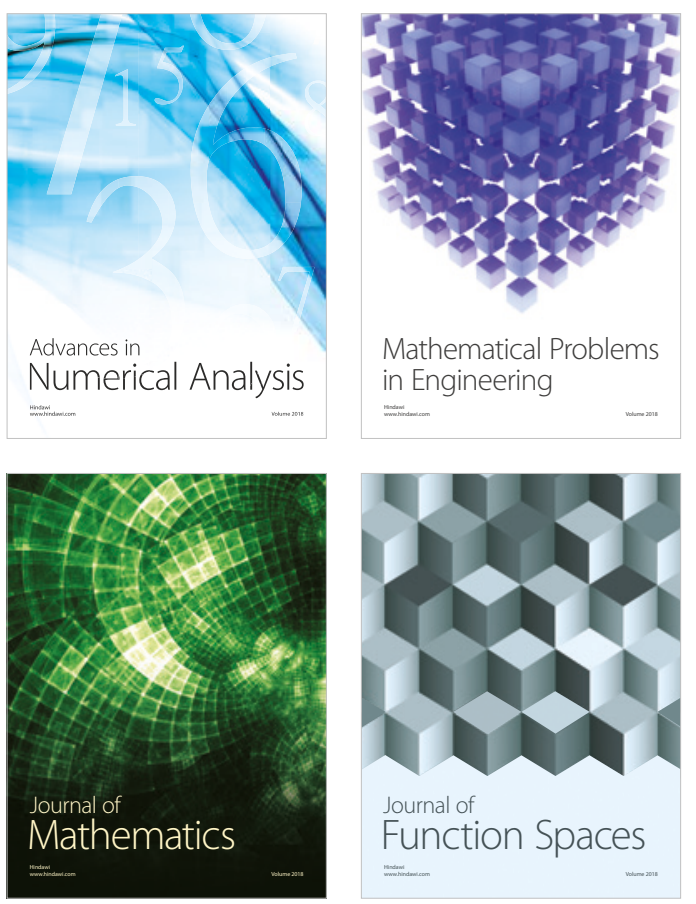

Mathematical Problems in Engineering

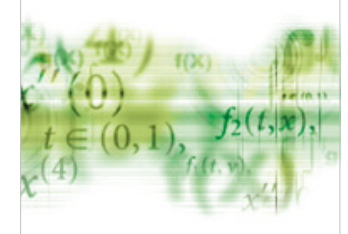

International Journal of

Differential Equations

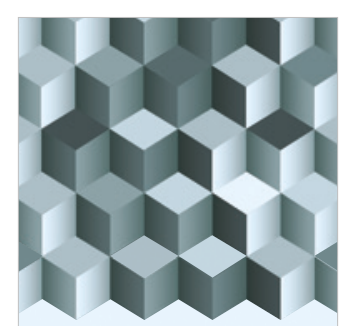

Journal of

Function Spaces
The Scientific

World Journal

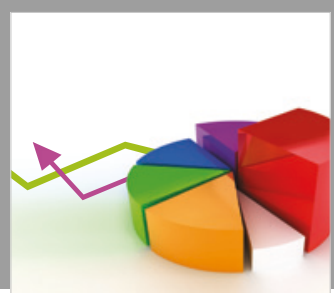

Journal of

Probability and Statistics
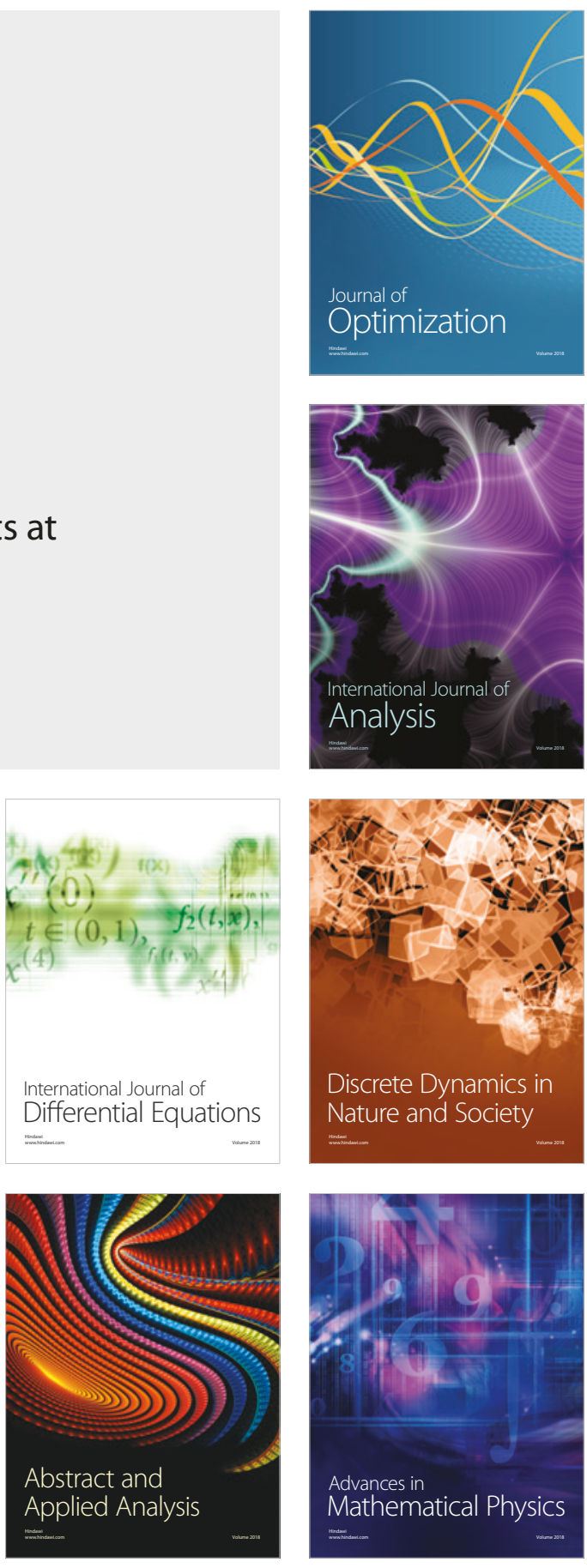